\title{
Urkunden und Briefe über das antihussitische Handelsverbot
}

\section{Charters and Letters Regarding the Trade Embargo Against the Czech Hussites}

\author{
Alexandra Kaar / kaar@hiu.cas.cz \\ Historický ústav AV ČR, Oddělení dějin středověku, CZ
}

\begin{abstract}
The present paper studies the charters and letters originating during the Catholic trade embargo first imposed against the Czech Hussites between 1420 and 1436, and reassumed in the late 1460s and early 1470s. The different types of documents are first studied with regard to their formal characteristics and their classification in terms of late medieval diplomatics. Secondly, lost correspondence is reconstructed in order to demonstrate the great void of missing documents, preventing us from truly grasping the widespread use of the written word during the Hussite Wars. Thirdly, the publication of papal and royal mandates enforcing the anti-Hussite embargo is analysed to demonstrate both the practical use of the documents in question, and their importance for Catholic anti-Hussite policy.
\end{abstract}

\section{Keywords}

Trade embargo; Trade, Hussites; Central Europe; Diplomatics; Sources; Writing in late medieval War 


\section{Einleitung}

Wirtschaftliche Zwangsmaßnahmen wie das Handelsverbot, das Papst Martin V. und König Sigismund im Frühling 1420 gegen die böhmischen Hussiten verhängten, stellen ein im ganzen Mittelalter verbreitetes, klassisches Kriegsmittel dar. ${ }^{1}$ Die Beschäftigung mit den Schriftstücken, die im Zusammenhang mit diesem antihussitischen Handelsverbot entstanden sind, fügt sich daher ein in die Forschungen zu Fragen der pragmatischen Schriftlichkeit im spätmittelalterlichen Krieg, die im Dezember 2018 auf dem Workshop präsentiert wurden, der diesem Zeitschriftenband zugrunde liegt. ${ }^{2}$ Anders als die übrigen hier versammelten Beiträge stellt die vorliegende Studie allerdings nicht eine bestimmte Quellengattung in den Mittelpunkt. Vielmehr werden die unterschiedlichen Arten von Schriftstücken näher beleuchtet, welche aus dem offenkundig intensiven pragmatischen Schriftgebrauch der katholischen Seite während des antihussitischen Handelsverbotes hervorgingen. Der Beitrag entwickelt entsprechend eine Art „Quellenkunde“ dieses Verbotes, in der Zuversicht, dass viele der an dem gewählten Material gewonnen Beobachtungen anschlussfähig sind für die Untersuchung von Schriftgut, welches aus anderen kriegerischen Auseinandersetzungen hervorgegangen ist.

$\mathrm{Zu}$ diesem Zweck werden zunächst die verschiedenen Typen von Urkunden und Briefen über das Handelsverbot vorgestellt und nach quellenkritischen Gesichtspunkten klassifiziert. Besonderes Augenmerk wird dabei auf diplomatische Aspekte gerichtet, welche Aussagen über den „Sitz“ dieser Schriftstücke im Alltagsleben der Hussitenkriege erlauben. Ausgehend von der im Rahmen des Workshops mehrfach thematisierten Beobachtung, dass das Ausmaß der pragmatischen Schriftproduktion im spätmittelalterlichen Krieg nur zu oft durch die fragmentarische Überlieferungslage verschleiert wird, untersucht der zweite Abschnitt, welche Aussagen über die heute nicht mehr existenten Urkunden und Briefen über das antihussitische Handelsverbot getroffen werden können. Damit zusammenhängend widmet sich der dritte und letzte Abschnitt dieser Studie schließlich der Publikation und Rezeption der genannten Schriftstücke, um der Allgegenwärtigkeit von Schrift im spätmittelalterlichen Krieg noch einmal zusätzlich Kontur $\mathrm{zu}$ verleihen.

1 Vgl. die Beispiele für mittelalterliche Handelsverbote und andere Arten von wirtschaftlichen Zwangsmaßnahmen bei Schmidt, Tilmann: Waffenembargo und Handelskrieg im Mittelalter. Vierteljahrschrift für Sozial- und Wirtschaftsgeschichte 93, 2006, S. 23-33; Stantchev, Stefan K.: The medieval origins of embargo as a policy tool. History of Political Thought 33, 2012, S. 373-399, hier S. 386-396. Zum antihussitischen Handelsverbot siehe jetzt Kaar, Alexandra: Wirtschaft, Krieg und Seelenheil. Papst Martin V., Kaiser Sigismund und das Handelsverbot gegen die Hussiten in Böhmen. Forschungen zur Kaiser- und Papstgeschichte des Mittelalters Beihefte zu J. F. Böhmer, Regesta Imperii 46. Wien - Köln - Weimar 2020, basierend auf der ungedr. Dissertation der Verfasserin, Wien 2017.

2 Internationaler Workshop „Diplomata bellica. Pragmatische Schriftlichkeit im spätmittelalterlichen Krieg“ (III. Brünner Workshop zu diplomatischen Studien), 7. Dezember 2018, Brünn, Philosophische Fakultät der Masaryk Universität. 


\section{Klassifizierung der Urkunden und Briefe über das antihussitische Handelsverbot}

Unter dem Blickwinkel der historischen Quellenkritik lassen sich die Quellen zum antihussitischen Handelsverbot in drei Kategorien unterteilen: 1) normative Quellen, 2) städtische bzw. diplomatische Korrespondenzen und chronikalische Berichte sowie 3) Quellen, die ihren Ursprung in städtischer und fürstlicher Verwaltungstätigkeit haben. ${ }^{3}$

Natürlicher Ausgangspunkt der Beschäftigung mit dem Thema „Handelsverbot“ ist die Auseinandersetzung mit den diesbezüglichen normativen Quellen. Dazu gehören neben den Bestimmungen des Kirchenrechts vor allem Urkunden des Papstes und seiner Legaten, König Sigismunds sowie diverser anderer Herrschaftsträger, die das antihussitische Handelsverbot einschärften. Hinsichtlich der kurialen Schreiben lässt sich mit Blick auf deren äußere Form zunächst festhalten, dass die üblichen Formen der spätmittelalterlichen Papsturkunde begegnen: litterae, Bullen sowie Legatenurkunden. ${ }^{4}$ Diese sind für gewöhnlich allgemein an die gesamte Christenheit adressiert, werden aber meist von zusätzlichen litterae flankiert, die den Kreis der Empfänger insofern spezifizieren, als dass sie die Verkündigung des Verbotes in einer bestimmten Diözese anordnen. ${ }^{5}$ In anderen Fällen lässt sich der faktische Adressat aus dem Überlieferungsort erschließen. ${ }^{6}$ Auffällig ist weiters, dass die - insgesamt nicht besonders zahlreichen - päpstlichen Schreiben über das antihussitische Handelsverbot häufig im Zusammenhang mit der Vorbereitung von Legationen, die das Kreuz gegen die Hussiten predigen sollten, entstanden. Die litterae, mit denen Papst Martin V. am 15. Jänner 1426 einen älteren Aufruf an alle Gläubigen, das Handelsverbot zu respektieren, erneuerte, datieren nur einen Tag vor dem Kreuzzugsaufruf, den der päpstliche Legat Giordano Orsini in diesem Jahr in Ungarn, Böhmen, Mähren und Meißen verkünden sollte. ${ }^{7}$ Ähnliches gilt für eine Bulle über das

3 Für eine ausführliche Diskussion der Quellengrundlage und der damit zusammenhängenden methodischen Herausforderungen vgl. Kaar, A.: Wirtschaft, S. 84-106.

4 Vgl. als Beispiel für litterae Acta Martini V. pontificis Romani 1417-1431 1-3. Ed. J. Eršil. Monumenta Vaticana res gestas Bohemicas illustrantia 7. Pragae 1996-2001, 2, S. 605, Nr. 1514, Martin V. an alle Gläubigen, 1426, Jänner 15, Rom; für eine Bulle Vetera monumenta historica Hungariam sacram illustrantia 2: Ab Innocentio PP. VI. usque ad Clementem PP. VII., 1352-1526. Ed. A. Theiner. Romae 1870, S. 209, Nr. 367, Regest Eršil, J.: Acta, 2, S. 829-830, Nr. 2236, Martin V. an alle Gläubigen, 1431, Jänner 9, Rom; für eine Legatenurkunde Urkundliche Beiträge zur Geschichte der Hussitenkriege in Böhmen vom Jahre 1419 an 1-2. Ed. F. Palacký. Prag 1873, 1, S. 336-338, Nr. 293, Branda da Castiglione an den Bischof von Regensburg, 1424, Mai 16, Blindenburg [Visegrád].

5 Vgl. Eršil, J:: Acta, 2, S. 605, Nr. 1515, Martin V. an den Bischof von Olmütz [Olomouc], 1426, Jänner 16, Rom, bezogen auf die litterae vom Vortag, ebd., S. 605, Nr. 1514, siehe oben, Anm. 4.

6 Vgl. die Parallelüberlieferung zu den eben zitierten allgemeinen litterae für Olmütz im Sächsischen Hauptstaatsarchiv Dresden, 10001 Ältere Urkunden, Nr. 6012, Martin V. an alle Gläubigen, 1426, Jänner 15, Rom, mutmaßlich für den Bischof von Meißen. Der genaue Empfänger ist allerdings unklar, da nach Ermisch, Hubert: Dresden und die Hussitenkriege. Mitteilungen des Vereins für Geschichte Dresdens 28, 1920, S. 41-90, hier S. 56 die Stadt Dresden einen Boten für die Überbringung dieser litterae entlohnte.

7 Siehe oben, Anm. 5 und 6. Zum Kontext und der von Orsini zu verkündenden Kreuzzugsbulle vgl. Studt, Birgit: Papst Martin V. (1417-1431) und die Kirchenreform in Deutschland. Forschungen zur Kaiser- und Papstgeschichte des Mittelalters Beihefte zu J. F. Böhmer, Regesta Imperii 23. Köln - Weimar - Wien 2004, S. 621. 
Handelsverbot vom 9. Jänner 1431, die in den Zusammenhang der Vorbereitungen für die ebenfalls auf einen neuen Kreuzzug abzielende Legation Giuliano Cesarinis gehört. ${ }^{8}$ In der Narratio heißt es dort zwar, Sigismund habe den Papst über Verletzungen des Handelsverbotes informiert und ihn gebeten, mit allen ihm zur Verfügung stehenden geistlichen Strafen gegen Schwarzhändler vorzugehen. ${ }^{9}$ Auch wenn es durchaus möglich ist, dass es eine solche Bitte tatsächlich gab, ${ }^{10}$ erscheint es angesichts des Ausstellungszeitpunktes eher unwahrscheinlich, dass Sigismunds Ersuchen tatsächlich der Grund dafür war, dass die Bulle zu eben diesem Zeitpunkt erlassen wurde. Vielmehr handelte es sich bei der Einschärfung des Handelsverbotes um eine gezielte Maßnahme der Kurie zur Vorbereitung ihrer neuen Kreuzzugsinitiative. Analog zu den im selben Zusammenhang entstandenen Beauftragungsschreiben und Vollmachten für die Legaten Martins V. waren dessen litterae über das Handelsverbot mutmaßlich „von vornherein für eine weite Verbreitung und starke Außenwirkung konzipiert “. ${ }^{11}$ Dies machte sie zu geeigneten Medien für die Propagierung des Kreuzzuges gegen die Hussiten. ${ }^{12}$

Parallel zur Kurie wurde das antihussitische Handelsverbot auch von den weltlichen Mächten propagiert. Die entsprechenden Mandate wurden der äußeren Form nach entweder als litterae clausae oder als offene Briefe, die der weiteren Verbreitung des Verbotes dienen sollten, ausgefertigt. Dies gilt z. B. für ein Schreiben Sigismunds an die Stadt Regensburg vom April 1424, auf das im Folgenden noch mehrfach zurückzukommen sein wird. ${ }^{13}$ Dieses Mandat, mit dem der König die Ratsherren aufforderte, ein im Herbst 1423 erlassenes Dekret des Konzils von Pavia-Siena über das antihussitische Handelsverbot umzusetzen, ${ }^{14}$ ist heute nur noch als Abschrift in der sogenannten „Hussitenchronik" des Andreas von Regensburg erhalten. Ursprünglich könnte es die Form von litterae patentes mit anhängendem Sekretsiegel gehabt haben, so wie ein im Original

8 Theiner, A.: Monumenta, 2, S. 209, Nr. 367 (siehe oben, Anm. 4). In den vatikanischen Registern folgt unmittelbar auf dieses Stück eine Urkunde über die Erweiterung der Legation Cesarinis für Böhmen, Mähren und Meißen um Deutschland, Ungarn und Polen. Die von Cesarini zu verkündende Kreuzzugsbulle in Eršil, J.: Acta, 2, S. 831-832, Nr. 2241, Martin V. an alle Gläubigen, 1431, Jänner 11, Rom.

9 Theiner, A.: Monumenta, 2, S. 209: Cum Carissimus in Christo filius noster Sigismundus Romanorum, Ungarie et Bohemie Rex Illustris ... inter cetera novissime nobis significaverit, quod nonnulli catholici deum ac fidem christianam contempnentes, victualia et alias res necessarias, ac subventionem Bohemis hereticis sepius subministrant; cumque preterea filiali sua devotione nos requisiverit, ut huiusmodi subventores penis a iure edictis et aliis oportunis remediis prosequeremur.

10 Vgl. etwa eine entsprechende Bitte Sigismunds an die Basler Konzilsväter in Deutsche Reichstagsakten 7-12, Deutsche Reichstagsakten unter Kaiser Sigmund (= DRTA). Edd. D. Kerler - H. Herre - G. Beckmann. Gotha - Göttingen 1878-1901, 11, S. 268, Nr. 139, Sigismund an das Konzil von Basel, 1433, November 9, Basel.

11 Studt, B.: Martin V., S. 16 (bezogen auf die von humanistisch geschulten päpstlichen Sekretären konzipierten Beauftragungsschreiben und Vollmachten).

12 Zur Frage der Publikation und Rezeption der Urkunden über das antihussitische Handelsverbot vgl. im Folgenden.

13 Palacký, F.: Urkundliche Beiträge, 2, S. 339-340, Nr. 294, Sigismund an die Stadt Regensburg, 1424, Mai 17, Blindenburg.

14 Das Konzil von Pavia-Siena (1423-1424) 2. Quellen. Ed. W. Brandmüller. Vorreformationsgeschichtliche Forschungen 16, II. Münster 1974, S. 20-22, Nr. 3, Dekret des Konzils von Pavia-Siena, 1423, November 8, Pavia. 
erhaltendes Schreiben Sigismunds auf Pergament an die Stadt Görlitz vom April 1431. ${ }^{15}$ Wahrscheinlicher ist allerdings, dass es sich um eine auf Papier ausgefertigte Urkunde mit verso aufgedrücktem Sekretsiegel handelte, so wie bei einem parallel zu dem Regensburger Stück an alle Städte in Schlesien adressierten Mandat desselben Ausstellers. ${ }^{16}$ Aufschlussreich im vorliegenden Zusammenhang ist, dass die Nürnberger Ratsherren Anfang Juni 1424 ihre Regensburger Amtskollegen um eine Kopie dieses Stückes baten. ${ }^{17}$ Das königliche Schreiben wird dabei ausdrücklich als gemeine schrift bezeichnet, d. h. als offener Brief, der offenbar über die Vermittlung Regensburgs unter den süddeutschen Städten verbreitet werden sollte, so wie es zwei Jahre zuvor schon mit einem anderen Mandat Sigismunds über das antihussitische Handelsverbot geschehen war. ${ }^{18}$

Unter diplomatischen Gesichtspunkten verdient weiters auch ein auf Pergament ausgefertigtes Mandat Sigismunds vom April 1431 an Rat und Bürger der schlesischen Metropole Breslau (polnisch Wrocław) Aufmerksamkeit. ${ }^{19}$ Bei diesem Schreiben handelt es sich um eine Parallelausfertigung zu dem eben erwähnten Mandat an Görlitz vom selben Tag, ${ }^{20}$ genauso wie dieses war es vermutlich ebenfalls mit einem (heute verlorenen) königlichen Sekretsiegel besiegelt. ${ }^{21}$ Im Gegensatz zu dem Görlitzer Stück besitzt die Breslauer Urkunde verso einen Registraturvermerk, wurde also wohl in die heute verlorenen böhmischen Register der Kanzlei Sigismunds eingetragen. Analog zu den Reichsregistern wurden darin wahrscheinlich hauptsächlich Urkunden rechtssetzenden Charakters aufgenommen, kaum jedoch Mandate und Briefe. ${ }^{22}$ Dieser etwas überraschende Befund erklärt sich durch den Inhalt des Breslauer Stückes. Sowohl die Görlitzer, als auch die Breslauer Ausfertigung beginnen mit der Aufforderung an die Adressaten, gegen alle vorzugehen, die dem hussitischen Feind speise, tranck, geczewg und ander notdurfft zufuren, in backen, brewen und ander gemeinschafft mit kawffen und verkauffen mit in treiben

15 Orig. Ratsarchiv Görlitz (= RAG), Urkunden, sub dato (262/210); Palacký, F.: Urkundliche Beiträge, 2, S. 208-209, Nr. 735, Sigismund an die Stadt Görlitz, 1431, April 12, Nürnberg.

16 Orig. Archiwum państwowe we Wrocławiu (= AP Wr), Dokumenty miasta Wrocławia, Sg. 1587; Geschichtsquellen der Hussitenkriege. Ed. C. Grünhagen. Scriptores Rerum Silesiacarum 6, Breslau 1871, S. 42-43, Nr. 57, Sigismund an die schlesischen Städte, 1424, Mai 17, Blindenburg. Vgl. zur Interpretation dieser und vergleichbarer Parallelausfertigungen hier im Folgenden.

17 Staatsarchiv Nürnberg (= StAN), Reichsstadt Nürnberg, Briefbücher des Inneren Rates (= BB), Nr. 6, F. 89r-v; Palacký, F.: Urkundliche Beiträge, 1, S. 344, Nr. 297, der Nürnberger Rat an den Rat der Stadt Regensburg, 1424, Juni 8, Nürnberg.

18 Vgl. DRTA 8, S. 114-115, Nr. 99, der Augsburger Rat an den Rat der Stadt Ulm, 1422, Februar 12, Augsburg. Vgl. dazu auch im Folgenden, Anm. 85.

19 Orig. AP Wr, Dokumenty miasta Wrocławia, Sg. 1866; Grünhagen, C.: Geschichtsquellen, S. 103, Nr. 144, Sigismund an die Stadt Breslau, 1431, April 12, Nürnberg.

20 Siehe oben, Anm. 15.

21 Vgl. die Beschreibung des Siegels in Grünhagen, C.: Geschichtsquellen, S. 103, Nr. 144.

22 Zur Registrierungspraxis in der Reichskanzlei zusammenfassend J. F. Böhmer, Regesta Imperii XI. Regesten Kaiser Sigismunds (1410-1437) nach Archiven und Bibliotheken geordnet. Hg. von K. Hruza. 1. Die Urkunden und Briefe aus den Archiven und Bibliotheken Mährens und Tschechisch-Schlesiens. Ed. P. Elbel. Wien - Köln - Weimar 2012, S. 20-21. 
und [die Hussiten] domit sterken. ${ }^{23}$ Das Stück für Breslau bleibt allerdings hier nicht stehen. Auf die Einschärfung des Handelsverbotes folgt ein zweiter, mit der Bekämpfung der angeblichen Kollaborateure inhaltlich eng verknüpfter Punkt. Nach Angabe der Urkunde hatten die Breslauer in der Stadt und den untertänigen Landgemeinden einen anslag zur Bekämpfung der Hussiten erlassen, d. h. wohl einen Feldzug ausgeschrieben und die Bereitstellung von Bewaffneten bzw. von Geldmitteln verlangt. ${ }^{24}$ Dieses Vorgehen wird ausdrücklich als Gott und dem König gefällig gebilligt und den Empfängern werden sehr weitreichende Vollmachten gegeben, um diesen „Anschlag“ zu fördern..$^{25}$ Der Befehl, im Auftrag des Königs das antihussitische Handelsverbot durchzusetzen, war also eng mit Inhalten verknüpft, die einerseits die Stellung des Breslauer Rates im Gefüge der schlesischen Fürstentümer stärkten, andererseits dessen grundherrliche Rechte innerhalb des städtischen Territorialbesitzes unterstrichen. Die Urkunde trägt daher eigentlich eher den Charakter eines Privilegs, wozu auch die prestigereichere Ausfertigung auf Pergament passt. Vom selben Tag gibt es darüber hinaus noch weitere Urkunden für Breslau, mit denen der König die Rechte der Stadt vermehrte. ${ }^{26}$ Diese Beobachtungen zeigen, dass auch bei jenen Urkunden, die das antihussitische Handelsverbot einschärften, die Empfänger mitunter in den Prozess der Ausstellung involviert waren und ein aktives Interesse am Zustandekommen solcher Mandate haben konnten. ${ }^{27}$

Neben päpstlichen und herrscherlichen Urkunden, die das antihussitische Handelsverbot einschärften, erscheinen einschlägige normative Bestimmungen schließlich noch in einer weiteren Kategorie von Schriftstücken, die die Zunahme pragmatischer Schriftlichkeit im spätmittelalterlichen Krieg spiegelt: Landfriedens-, Landesverteidigungsbzw. Heerzugsordnungen und andere verwandte Quellen. Die Bandbreite geht dabei von einem schlichten Nebensatz über das Abschneiden hussitischer Nachschubwege ${ }^{28}$ bis hin zum sogenannten Edikt von Welun [Wieluń], einem programmatischen Manifest,

23 Zitat RAG, Urkunden, sub dato (262/210) (siehe oben, Anm. 15). Wortgleich in AP Wr, Dokumenty miasta Wrocławia, Sg. 1866.

24 Bei diesem „Anschlag“ handelte es sich wohl um Vorbereitungen für einen Ende Mai 1431 unternommenen Vorstoß schlesischer Truppen gegen den hussitischen Stützpunkt in Nimptsch [Niemcza], vgl. Grünhagen, Colmar: Die Hussitenkämpfe der Schlesier 1420-1435. Breslau 1872, S. 215.

25 AP Wr, Dokumenty miasta Wrocławia, Sg. 1866: [Wir] befelhen ... euch, ... wer zu sulchem anslag und loblichen sachen nicht helffen wolt und villicht etlich weren an den grenitzen oder anderswo gesessen, heren, stet, mann, gebauern und ander inwoner, die sich mit den ketzern gesatzt, abgetedingt und gefriedet hetten und den ketzern furderung teten, das ir die mit dem swert und feuer dorzu bringet und notet, das sie nach dem obgenanten anslag wider die ketzer helffent und faren, als sich das geburen wirt.

26 Vgl. J. F. Böhmer, Regesta Imperii. XI. Die Urkunden Kaiser Sigmunds (1410-1437) (= RI XI). Ed. W. Altmann. Innsbruck 1896-1900, 2, S. 166, Nrr. 8456-8457, beide 1431, April 12, Nürnberg.

27 Zum Zusammenwirken solcher Top-down- und Bottom-up-Prozesse vgl. Kaar, Alexandra: Neue Mittel der Kriegsführung? König/Kaiser Sigismund und das Handelsverbot gegen die Hussiten in Böhmen. In: Heilige - Helden - Wüteriche. Herrschaftsstile der Luxemburger (1308-1437). Hg. von M. Bauch u. a. Forschungen zur Kaiser- und Papstgeschichte des Mittelalters Beihefte zu J. F. Böhmer, Regesta Imperii 41. Köln - Weimar - Wien 2017, S. 223-242, hier 228-233, sowie dies.: Wirtschaft, S. 281-294.

28 Siehe z. B. DRTA 9, S. 34-40, Nr. 31, hier S. 38, § 27, allgemeine Heerzugsordnung, 1427, kurz vor Mai 4, Frankfurt: Item die herren sullen mit hilfe der stete bestellen ... das dann die nechsten slosse oder stete im lande zu Beheym gelegen, die noch cristen sein, das die bestalt werden und besaczt zu teglichem kriege, also das den keczern keine fu'rderung geschee notdurft zugelegt oder zugefurt werde. 
mit dem der polnische König Wladislaw II. Jagiello im April 1424 die Beschlüsse einer Reichsversammlung promulgierte, die u. a. die wirtschaftliche Unterstützung von Hussiten zum Majestätsverbrechen erklärte. ${ }^{29}$

Die zweite Kategorie von Quellen, die das Handelsverbot tangieren, d. h. städtische Korrespondenzen über Kreuzzugsvorbereitungen oder die Beschlagnahme von Waren unter dem Vorwurf des Schwarzhandels sowie die diplomatischen Korrespondenzen der involvierten Herrscher und Papst Martins V. kann an dieser Stelle nur kurz gestreift werden. Diese Briefe können sehr detaillierte Informationen über die Umsetzung bzw. die Umgehung des antihussitischen Handelsverbotes enthalten, so wie beispielsweise ein hochinteressantes Schreiben Sigismunds an die Adresse des eben genannten polnischen Königs Wladislaw Jagiello vom April 1424, in dem Sigismund denselben aufforderte, dem polnischen Bleiexport nach Böhmen Einhalt zu gebieten, ${ }^{30}$ oder einige Briefe, mit denen der Nürnberger Rat Beschwerde gegen die angeblich ungerechtfertigte Konfiskation von Nürnberger Warenzügen an der Grenze zu Böhmen einlegte. ${ }^{31}$ Eine umfassende wirtschaftsgeschichtliche Analyse dieser und vergleichbarer Korrespondenzen ist bereits an anderer Stelle erfolgt. ${ }^{32}$ Die vorliegende Studie beschränkt sich daher darauf, diese Quellen heranzuziehen um Informationen über die Publikation und Propagierung des antihussitische Handelsverbotes zu gewinnen, ebenso wie über das Verhältnis zwischen ehemals existierenden und heute noch vorhandenen Schriftstücken. Im Folgenden wird entsprechend an gegebenem Ort noch einmal ausführlicher auf diese Kategorie von Quellen zurückzukommen sein.

An dieser Stelle ist stattdessen etwas ausführlicher auf die dritte Kategorie von Quellen zum antihussitischen Handelsverbot einzugehen, d. h. jene Schriftstücke, die ihren Ursprung in städtischer und fürstlicher Verwaltungstätigkeit haben. Unter diese Kategorie fällt eine ganze Reihe unterschiedlicher Quellengattungen. Zu nennen sind hier etwa Rechnungen, die Informationen über das Angebot von Waren, die dem Handelsverbot

29 Palacký, F.: Urkundliche Beiträge, 1, S. 331-333, Nr. 288, hier S. 332, Wladislaw Jagiello an alle seine Untertanen, 1424, April 9, Welun: Inhibemums etiam sub eisdem poenis omnibus mercatoribus et aliis hominibus cujuscunque conditionis fuerint, ut a modo et in posterum nullas res venales, et praesertim plumbum, arma, esculenta ac potulenta ad Bohemiam ducere praesumant vel portare. Zu diesem Dokument vgl. zusammenfassend Kaar, A.: Wirtschaft, S. 274-276.

30 Palacký, F.: Urkundliche Beiträge, 1, S. 333-334, Nr. 290, hier S. 334, Sigismund an Wladislaw Jagiello, 1424, März 31 oder Anfang April, Diósgyőr: Insuper V Vam Fr. cordialissime rogamus, ut ... omnibus et singulis vestris subditis ... interdicere et inhibere velitis, quod nullus regum Bohemie in auxilium Bohemorum hereticorum intrare uel plumbum uel alias quascunque res uel merces illac eisdem afferre seu cum ipsis aliquam communionem siue comercium habere et facere presumat. Eine ausführliche Diskussion dieses Stücks bei Kaar, A.: Wirtschaft, S. 162-165 und 272-274.

31 Vgl. dazu Polívka, Miloslav: Wirtschaftliche Beziehungen Nürnbergs mit den „böhmischen Ketzern“ in den Jahren 1419 bis 1434. Haben die Nürnberger mit den Hussiten Handel betrieben? Mitteilungen des Vereins für Geschichte der Stadt Nürnberg 86, 1999, S. 1-19, sowie neu Kaar, Alexandra: Granatäpfel, Pfeffer und ein Braukessel für die Ketzer. Zum Handel mit Waren des gehobenen Bedarfs zwischen Böhmen und seinen Nachbarländern in den Hussitenkriegen. Mitteilungen des Instituts für Österreichische Geschichtsforschung 126, 2018, S. 354-360.

32 Vgl. die oben in Anm. 30 und 31 genannte Literatur sowie allgemein Kaar, A.: Wirtschaft. 
zum Trotz im hussitischen Böhmen erhältlich waren, enthalten können, ${ }^{33}$ oder gelegentlich auch über die Verfolgung angeblicher Hussitenhändler. ${ }^{34}$ Weitere Beispiele für die Vielfalt des vom antihussitischen Handelsverbot hervorgerufenen Verwaltungsschriftgutes sind etwa Urkunden, die die Absolution von Schwarzhändlern von der Sünde des Hussitenhandels betreffen, ${ }^{35}$ oder jene Handelslizenzen, die das Papsttum ab den 1470er Jahren an ausgewählte Empfänger vergab, nachdem das Handelsverbot im Zuge des Kreuzzuges gegen den damaligen böhmischen König Georg von Podiebrad wiederbelebt worden war. ${ }^{36}$ Hier soll der Fokus allerdings auf zwei anderen Quellentypen liegen, welche das Ausmaß der von dem antihussitischen Handelsverbot hervorgerufenen pragmatischen Schriftlichkeit besonders gut illustrieren: einerseits Schriftstücke, die aus der mittelalterlichen Strafverfolgung hervorgingen, konkret Geständnisse, Urfehdebriefe, Bürgschaftserklärungen und ähnliche justizielle Quellen; andererseits sogenannte Förderbriefe, d. h. verschiedene Formen von alltäglichen Gebrauchsschriftstücken, die der Beglaubigung der Identität ihres Inhabers und/oder dessen Empfehlung an eine Obrigkeit, in deren Herrschaftsgebiet der Inhaber unterwegs war, dienten.

Justizielle Quellen sind außerordentlich wertvoll um einerseits die Umgehung des antihussitischen Handelsverbotes, andererseits dessen praktische Umsetzung zu untersuchen. Allerdings ist es gerade hier nicht immer einfach, eine unzweifelhafte Verbindung zu unserem Thema herzustellen. Erfreulich explizit zum Vergehen der Delinquenten äußern sich beispielsweise drei Notariatsinstrumente, die der Nürnberger Rat im September 1472 über das Verhör und die Bestrafung einiger Bürger anfertigen ließ, die angeblich dem erneuerten Handelsverbot zuwider gehandelt hatten. ${ }^{37}$ Diese drei Urkun-

33 Vgl. etwa die Auswertung der Rechnungen der königlichen Burg Karlstein [Karlštejn] bei Čechura, Jaroslav: Zum Konsumniveau in Ostmittel- und Westmitteleuropa in der ersten Hälfte des 15. Jahrhunderts. In: Westmitteleuropa, Ostmitteleuropa. Vergleiche und Beziehungen. Festschrift für Ferdinand Seibt zum 65. Geburtstag. Hg. von W. Eberhard u. a. München 1992, S. 175-184 und Garkisch, Miloš: Běžný život na hradě Karlštejně za husitských válek ve světle hradních účtů [Das Alltagsleben auf Burg Karlstein während der Hussitenkriege im Licht der dortigen Rechnungen]. In: Sborník k poctě Evy a Karla Waskových, západočeských archivářů. Hg. von M. Wasková. Plzeň 2011, S. 77-89.

34 Vgl. etwa die sogenannten Görlitzer Ratsrechnungen, gedruckt in Codex Diplomaticus Lusatiae Superioris II. Urkunden des Oberlausitzer Hussitenkrieges und der gleichzeitigen die Sechslande angehenden Fehden 1-2. Ed. R. Jecht. Görlitz 1896-1903, hier 1, S. 406, zu 1427, November 30, Görlitz: Ausgaben für die Inhaftierung zweier „Böhmen“ wegen angeblicher Ketzerei und Schwarzhandels.

35 Vgl. z. B. Orig. Bayerisches Hauptstaatsarchiv München, Abteilung I (Ältere Bestände), Hochstift Passau Urkunden, Nr. 1438, Martin V. für den Bischof von Passau, 1429, April 25, Rom. Ausführlich zu dieser Quellengattung Kaar, A.: Wirtschaft, S. 226-229.

36 Eine Serie solcher Lizenzen hat sich im Staatsarchiv Nürnberg erhalten, vgl. als Beispiel lediglich das chronologisch letzte Exemplar von 1495, StAN, Reichsstadt Nürnberg, Päpstliche und fürstliche Privilegien, Urkunden, Nr. 396, Alexander VI. an die Stadt Nürnberg, 1495, Juli 13, Rom. Zu diesem „Zweiten“ antihussitischen Handelsverbot vgl. jetzt neu die Bemerkungen in Kaar, Alexandra: Embargoing „heretics“ in fifteenth-century Central Europe. The case of Hussite Bohemia. Journal of Medieval History 46, 2020 (im Druck).

37 StAN, Reichsstadt Nürnberg, D-Laden, Urkunden, Nrr. 566-568, hier Nr. 566, 1472, September 18 bis 21 , Nürnberg: [Die Nürnberger Ratsherren] haben verpotett, beschickt und ervordern lasen den ersamen Cuntzen Schuler, demselben fuergehalten der maynung gleich: Es was an einen erbern rate zu Nurmberg gelanget, wye [er] hantirung und gewerb in das kunigreich gein Beheim, so dann von unserm allerheyligsten in Got vater, dem babst, gemeinschafft verpoten sy, nochmals handell und treybe ..., [was] einem erbern rate ... zu gestaten, zu leyden, noch zu 
den verdanken ihren Detailreichtum wohl ihrem Charakter als Protokolle über ein formalisiertes mündliches Gerichtsverfahren. Die - wenigen - überlieferten Urfehdebriefe und Bürgschaftserklärungen, die Kontakte zu den Hussiten als Vergehen des Inhaftierten nennen, sind hingegen üblicherweise deutlich knapper formuliert. Der ausführliche Urfehdebrief des ehemaligen Chamer Bürgers Ulrich Kursner, welcher im Sommer 1424 bei seiner Entlassung aus dem Gefängnis Pfalzgraf Johanns von Neumarkt-Pfalz angab, er sei gefasst worden, während er mit den ungelewbigen pesen hussen und keczern gemeinschafft het mit kauffen und verkauffen ist die Ausnahme. ${ }^{38}$ Häufiger sind knappe Angaben nach dem Muster des folgenden typischen Eintrags aus den sogenannten Breslauer Signaturbüchern: ${ }^{39}$ Mehrere Bürgen verbürgen sich darin für das künftige Wohlverhalten eines gewissen Melchior Hoff, der ins Breslauer Gefängnis gekommen war, weil her den ketzern uff Meristaw ${ }^{40}$ wieder die heilige kirche und diesen landen bey gelegin und gehulffen hat. ${ }^{41}$ Worin genau Hoffs Vergehen bestand, bleibt unklar. Die „Dunkelziffer“ von angeblichen oder tatsächlichen Hussitenhändlern, die sich in diesen justiziellen Quellen verbergen, ist daher wahrscheinlich höher, als man auf Basis der Urkundenformeln nachweisen kann. Selbiges gilt mutmaßlich zumindest bis zu einem gewissen Grad auch für die durchaus beachtliche Zahl an Urfehdebriefen und Bürgschaftserklärungen aus der Hussitenzeit, die nicht näher auf das Vergehen des/der Delinquenten eingehen. ${ }^{42}$

Aus dem Vorangehenden dürfte deutlich geworden sein, dass die wirtschaftlichen Beziehungen zwischen Böhmen und seinen Nachbarländern ebenso wie diejenigen zwischen Hussiten und Katholiken innerhalb des Königreichs trotz des antihussitischen Handelsverbotes mehr oder weniger ungestört fortbestanden. ${ }^{43}$ Diesem Umstand verdanken wir

gedulden nicht zyme noch gepuere. ... Deßgleichen Niclasen Rosenkrantz und Friderichen Hertzogen, gastgebern und wirtt zu Nurmberg, verpotet und ervordert deßhalben, das an einen erbern rate daselbs gelangt het, wye sye dyejenen auß dem konigreich zu Beheim, das dann bebstlichen verboten were, hawsen und herberten, eczten und trenkten, deshalb so streflichen verboten werde nach inhalt der bebstichen gebote.

38 Orig. Archiv Historischer Verein für Oberpfalz und Regensburg, Urkunde Nr. 194, Urfehde Ulrich Kursners für Johann von Pfalz-Neumarkt, 1424, Juli 8.

39 Bei diesen handelt es sich um eine Serie von Gerichtsbüchern, in die u. a. Urfehden und Bürgschaftserklärungen für aus dem Breslauer Gefängnis entlassene Gefangene eingetragen wurden.

40 Laut Grünhagen, C.: Geschichtsquellen, S. 161, Anm. 2 zu identifizieren mit Märzdorf [Żelazna] bei Grottkau [Grodków].

41 Mitteilungen aus den Breslauer Signaturbüchern. Ed. O. Stobbe. Zeitschrift des Vereins für Geschichte und Alterthum Schlesiens 8, 1867, S. 151-166, 438-453, hier S. 151-152, Nr. 141, zum Jahr 1430.

42 Vgl. dazu die Ergebnisse Johannes Kaskas, laut dem in den von ihm untersuchten spätmittelalterlichen Urfehdebriefen aus Wien, Krems, Stein und Enns für den Zeitraum von 1401 bis 1425 in $34,5 \%$ der Urkunden das Delikt nicht spezifiziert wird. Von 1426 bis 1450 beläuft sich der Anteil immerhin noch auf $18,2 \%$, obwohl in den ab diesem Zeitpunkt zahlenmäßig dominierenden Wiener Urfehdebriefen der Haftgrund üblicherweise angegeben wird. Kaska, Johannes: Analyse ausgewählter Urfehdebriefe des österreichischen Raumes im Spätmittelalter. Wien 2013 (Ungedr. Diplomarbeit), S. 49-50. Die Regensburger Urfehdebriefe, in denen unbestimmbare Delikte lediglich 2,5\% der Vergehen ausmachen, sind im spätmittelalterlichen Reich diesbezüglich eher der Sonder- als der Regelfall, vgl. Wernicke, Steffen: Von Schlagen, Schmähen und Unendlichkeit. Die Regensburger Urfehdebriefe im 15. Jahrhundert. In: Kriminalitätsgeschichte. Beiträge zur Sozial- und Kulturgeschichte der Vormoderne. Hg. von Andreas Blauert - Gerd Schwerhoff. Konflikte und Kultur: Historische Perspektiven 1. Konstanz 2000, S. 379-404, hier S. 389.

Zur umstrittenen Frage nach den Effekten und der Effizienz des antihussitischen Handelsverbotes vgl. 
die bereits genannten Förderbriefe, ${ }^{44}$ auf die hier etwas ausführlicher eingegangen werden soll, da sie ein exzellentes Beispiel für den intensiven Gebrauch von Schriftstücken im spätmittelalterlichen Krieg darstellen. In den zeitgenössischen Quellen werden diese Urkunden meist schlicht als „Briefe“, „Kundschaft“ oder „Zettel“ bezeichnet. Ihre äußere Form dürfte variiert haben: von drei im Egerer Archiv ausnahmsweise im Original erhaltenen Stücken aus dem Herbst 1428 wurden zwei als litterae patentes mit recto unter dem Text aufgedrücktem Siegel ausgefertigt, eines als litterae clausae. ${ }^{45}$ Schon in Friedenszeiten waren sie ein weit verbreitetes Mittel zur Kontrolle des Verkehrs auf mittelalterlichen Handelsstraßen. Unter den Bedingungen der Hussitenkriege musste ihnen nochmals gesteigerte Bedeutung zukommen. Auf die Gründe dafür deutet etwa einer der eben erwähnten Förderbriefe aus Eger hin, mit dem zwei Reisende sich im Herbst 1428 vom Pilsner Rat nicht mehr nur ihre Identität und ihren guten Leumund, sondern auch ihre katholische Rechtgläubigkeit bestätigen ließen. ${ }^{46}$

Angesichts der hier durchklingenden weit verbreiteten Furcht der Katholiken vor Unterwanderung durch die Hussiten überrascht es nicht, dass das Prinzip der Förderbriefe während der Hussitenkriege zumindest fallweise systematisch für polizeiliche Zwecke adaptiert wurde. ${ }^{47}$ So versuchte etwa Herzog Albrecht V. von Österreich im Winter 1431/32 ein elaboriertes System einzuführen, um seine österreichischen Städte vor hussitischen Spionen und Saboteuren zu schützen. In einem Mandat an die seit 1421 an ihn verpfändete südböhmische Stadt Budweis [České Budějovice] gibt der Herzog im November 1431 an, er sei informiert worden, dass immer wieder hussitische Kundschafter als Kaufleute getarnt versuchten, in Österreich zu spionieren. ${ }^{48}$ Er habe seine österreichischen Städte daher angewiesen, fremde Fuhr- und Kaufleute nur noch dann einzulassen, wenn sie sich mittels einer briefleich kuntschefft als Untertanen Albrechts

Kaar, Alexandra: Business as usual? Sigismund's trade privileges for the royal towns of Bohemia. Husitský Tábor 22, 2018, S. 34-53, hier S. 46-49, sowie zusammenfassend dies.: Wirtschaft, S. 303-312.

44 Vgl. Artikel Förderbrief. Deutsches Rechtswörterbuch, online unter http://drw-www.adw.uni-heidelberg. de/drw-cgi/zeige?index=lemmata\&term=foerderbrief\&lastterm=foerderung, zusammen mit ebd., Artikel Förderungsbrief. http://drw-www.adw.uni-heidelberg.de/drw-cgi/zeige?index=lemmata\&term=Foerderun gbrief\#F\%C3\%B6rderungbrief-a. (Zugriff 23. Jänner 2019). Ich danke den TeilnehmerInnen des Brünner Workshops, namentlich Ondřej Schmidt und Stanislav Bárta, für Anregungen hinsichtlich Definition und Benennung dieses Typs von Schriftstücken.

45 Orig. Státní okresní archiv (= SOkA) Cheb, Archiv města (= AM) Cheb, Kart. 504, Fasz. 695, Nrr. A-2985/2, 3 und 5, der Pilsner Rat an den Rat der Stadt Eger [Cheb], 1428, September 20 und 22 bzw. Dezember 7, Pilsen [Plzeň]. Zur Frage der Überlieferung siehe im Folgenden unten.

46 Ebd., Nr. A-2985/2; Palacký, F.: Urkundliche Beiträge, 1, S. 641, Nr. 541, der Pilsner Rat an den Rat der Stadt Eger, 1428, September 20, Pilsen: [Wir] lassen ewr frewntschafft wissen, daz die gegenbürtig Nicklas und Petr unser mitwaner und frume kristen sind.

47 Vgl. zu der weit verbreiteten Hussitenfurcht ausführlich Kaar, A.: Wirtschaft, S. 239-251.

48 Orig. SOkA České Budějovice, AM České Budějovice, Chronologische Reihe, Sg. 1431/1, zusammen mit der beigeschlossenen Kopie eines undatierten Mandats desselben Ausstellers an eine ungenannte österreichische Stadt (Freistadt?); Palacký, F.: Urkundliche Beiträge, 2, S. 248-249, Nr. 770, Albrecht V. an den Rat der Stadt Budweis, 1431, November 8, Wien: Wir sein kuntleich underweiset worden, daz die veind von Behem und von Merhern durch die furlewt, die in unser stet gen Osterreich umb salcz, wein und ander notdurft varent, manig kuntscheff auzrichten, das uns und den unsern zu schaden kumbt. 
ausweisen konnten. ${ }^{49}$ Albrecht forderte die Budweiser daher auf, ihre Leute mit solchen Förderbriefen auszustatten. Dies sollte den Verkäufern garantieren, dass es sich bei ihren Kunden nicht um hussitische Kundschafter handelte, und dass ihre Waren nur nach Budweis bzw. an andere Anhänger der katholischen Seite geliefert und weiterverkauft würden, und nicht an Hussiten. ${ }^{50}$ Entsprechend legte der Herzog den Budweisern auch ans Herz, sich gut zu überlegen, wem sie einen solchen Förderbrief ausstellen wollten. ${ }^{51}$ Dieses System wurde anschließend auch auf den Verkehr zwischen den in Albrechts Besitz befindlichen katholischen mährischen Städten ausgedehnt. Aus einem Mandat vom Februar 1432 an die herzoglichen Amtsträger geht hervor, dass die von den Städten zu Versorgungszwecken angeworbenen Fuhrleute bei jeder Fahrt mit einem neuen, vom Auftraggeber besiegelten Förderbrief ausgestattet werden sollten, in dem die beförderten Waren genau aufgelistet wurden. ${ }^{52}$ Diese Maßnahme sollte sicherstellen, dass diese Versorgungsfahrten nicht zum Schmuggel von Gütern ins hussitische Lager genutzt wurden. Albrecht informierte seine Amtsträger über diese Regelungen, damit sie bei ihren Kontrollen die von den herzoglichen Städten angeworbenen Fuhrleute unbehelligt ziehen ließen. Allerdings sollten sie die Ladelisten genau kontrollieren und unrechtmäßig transportiertes Gut umgehend beschlagnahmen. ${ }^{53}$

Mutmaßlich auf ähnliche Vorschriften des Egerer Rates gehen die drei bereits genannten Förderbriefe aus dem Herbst und Winter 1428 zurück, die sich im Original im Stadtarchiv Eger erhalten haben. ${ }^{54}$ Mit einer dieser Urkunden verbürgt sich der Pilsner Rat, wie erwähnt, für die Rechtgläubigkeit zweier Einwohner von Pilsen. ${ }^{55}$ Der zweite Förderbrief bestätigt, dass eine gewisse Katharina Labutin schwere Schäden bei einem Brand erlitten hatte, ${ }^{56}$ der dritte beglaubigt die Inhaber ohne nähere Angabe von

49 Ebd.: Nu haben wir bey denselben unsern steten in Osterreich bestellet und geordnet, daz man in disen leuffen kainen fromden wagen sol inlassen, noch mit salcz, wein oder anderer war damit hanndeln, nur es sein solich wegen, die ew und andern unsern steten und geslossen, die wir in nemleich haben geschriben geben, zugehorn und darumb briefleich kuntschefft haben.

50 Ebd.: Davon ist unser maynung, ob ewr furlewt hinfur umb salcz, wein oder andere war gen Osterreich varn [= fahren] und arbaitten wellen, daz ir in dann ewr brief gebt, damit man ain wissen hab, daz si die ewrn sein, und das salcz oder ander war ... ew, ... und nicht den veinden zufurn, noch in das verrer verkauffen, und daz dieselben veind hinfur nicht mugn solich kuntschefft durch die fromden furlewt, die in genaigt sind, auzgerichten.

51 Ebd.: Davon ist unser maynung und wellen, daz ir in den sachen fleissig seyt und kainen andern, denn den ewrn und die ew zu ghorent, solich kuntschefft gebt.

52 Elbel, Petr: „Pravé, věrné a křestanské přiměřie ... “ Dohody o příměří mezi husity a stranou markraběte Albrechta na jižní Moravě [„Ein echter, treuer und christlicher Waffenstillstand ... “ Waffenstillstandsverträge zwischen den Hussiten und der Partei Markgraf Albrechts in Südmähren]. Brno 2016, S. 100-101, Nr. 15, hier S. 101, Albrecht V. an seine mährischen Amtsträger, 1432, Februar 13, Wien: den selben furleüten, den sie [= Albrechts mährische Städte] ier hab und guett also werden auslegen wellen, sie albeg zw yeder vartt newen brief unnder der statt insigel, da daz guet gehebt [= aufgelistet] wiert, geben, damit aigentlejych erkant werde, waz sy also von einer statt zw der andern furen wellent unnd nicht andrst wohÿn.

53 Ebd.: Was ir aber solicher war findet, die nemblich inn dem brieff nicht wer begriffen, der sollet $\ddot{y}$ ew underwinden.

54 Siehe oben, Anm. 45.

55 Siehe oben, Anm. 46.

56 Orig SOkA Cheb, AM Cheb, Kart. 504, Fasz. 695, Nr. A-2985/3, der Pilsner Rat an den Rat der Stadt Eger, 1428, September 22, Pilsen. 
Details als Pilsner mitwoner. ${ }^{57}$ Die Egerer werden weiters gebeten, den Inhabern der Förderbriefe zu gestatten, ihre Einkäufe in ihrer Stadt zu tätigen, und sie unbehelligt mit ihren Gütern nach Pilsen zurückkehren zu lassen. Die Aussteller garantieren weiter, dass die Genannten ihre Güter anderswohin nicht füren, dann her zu uns und in unser stat. In dem Brief für Katharina Labutin, mutmaßlich eine Krämerin, heißt es zusätzlich, dass diese die gekauften Waren nur in Pilsen und nur an Pilsner Bürger verkaufen werde..$^{58}$ Zusammengenommen deutet der Inhalt aller drei Schreiben darauf hin, dass der Egerer Rat damals gezielt Maßnahmen setzte, um den Weiterverkauf von in Eger erworbenen Gütern an den hussitischen Feind zu unterbinden. Dazu gehörte möglicherweise die verstärkte Kontrolle der Identität, des Leumundes und der Rechtgläubigkeit der in die Stadt kommenden Händler durch die überlieferten und vergleichbare Schriftstücke. ${ }^{59}$

Förderbriefe stellten allerdings nicht nur für Obrigkeiten Mittel der Kontrolle des Handelsverkehrs dar. Häufiger noch erwirkten reisende Kaufleute von sich aus solche Schreiben, um auf diese Weise ihr Risiko zu verringern. Sie versicherten sich so des Rückhaltes ihrer städtischen Gemeinden, die mit diesen Schreiben quasi ihren Namen und ihr Ansehen auf den Inhaber des Förderbriefes übertrugen. Aus diesem Grund konnte diese Kopplung ihrerseits zu diplomatischen Verstimmungen führen, wenn etwa Waren unter dem Verdacht des Hussitenhandels beschlagnahmt wurden, obwohl deren Besitzer entsprechende Förderbriefe besessen hatten. So erging es etwa einigen Kaufleuten aus der katholischen mährischen Stadt Olmütz, die vermutlich irgendwann im Jahr 1426 unter dem Verdacht rechte ketczer [zu] sein und den ketczern zu[zu]furen im schlesischen Liegnitz [Legnica] inhaftiert, und deren Güter beschlagnahmt wurden. Der Olmützer Rat wandte sich daraufhin an den Liegnitzer Rat, um zu bestätigen, dass die gefangenen Kaufleute uns und nicht den ketczern ware zufurten..$^{60}$ Bemerkenswerterweise scheinen die Olmützer dabei vor allem an der Verletzung ihrer Förderbriefe Anstoß genommen zu haben, jedenfalls bemerkten sie einigermaßen pikiert, sie wunderten sich, das unser brief und schreiben von ewr weisheit so klein gewegen würd, sintemolen wir ewern brieffen so kristlichen glawben wolden als ewer gegenwurtigen worten.

Das System der obrigkeitlichen Kontrolle von Handelsverkehr mittels Förderbriefen trug also einerseits den Keim für politische Auseinandersetzungen innerhalb der katholischen Partei in sich ${ }^{61}$ Andererseits erwies es sich offenbar in der Praxis nicht immer als so zweckdienlich wie die Urheber gehofft hatten. Aus einem Mandat Herzog Albrechts V.

57 Ebd., Nr. A-2985/5, der Pilsner Rat an den Rat der Stadt Eger, 1428, Dezember 7, Pilsen.

58 Ebd., Nr. A-2985/3, der Pilsner Rat an den Rat der Stadt Eger, 1428, September 22, Pilsen: wenn sy des anderswo hin nicht füret, dan her und daz alhie unsern mitpurgern verkauffet.

59 Vgl. dazu auch andere Hinweise auf erhöhte Wachsamkeit gegenüber mutmaßlichen Schwarzhändlern im bayerisch-böhmischen Grenzraum im Herbst/Winter 1428, die sich aus den Nürnberger Korrespondenzen gewinnen lassen, StAN, BB Nr. 8, F. 87v und 91r-v, der Nürnberger Rat an Heimeran Nothaft/Heinrich Nothaft, 1428, November 19 bzw. 26, Nürnberg; ebd., F. 93r, dies. an Johann von Pfalz-Neumarkt/ den Landschreiber zu Sulzbach, 1428, Dezember 2, Nürnberg.

60 SOkA Olomouc, AM Olomouc, Knihy, Sg. 677, Inv. č. 95a, sogenanntes Briefbuch des Wenzel von Iglau (= Olmützer Briefbuch), F. 167v, der Olmützer Rat an den Rat von Liegnitz, 1426 (?), Olmütz.

61 Vgl. in diesem Zusammenhang z. B. auch Kaar, A.: Wirtschaft, S. 210-214 für die umfänglichen diplomatischen Verwicklungen, die sich aus der Verhaftung der mit hussitischen Geleitbriefen ausgestatteten 
vom Juni 1426 erfahren wir etwa, dass in Budweis damals schon einmal ein System von Förderbriefen in Kraft gewesen war, mit denen sich jeder ausweisen musste, der die Stadt mit Waren betrat oder sie wieder verließ ${ }^{62}$ Der Herzog wies seinen Hauptmann mit besagtem Mandat an, diese Kontrollen aufzuheben, da die Budweiser sich bei ihm beklagt hatten, dass sie ihnen insofern zu Schaden gereichten, als dass die Landbevölkerung der umständlichen Kontrollen wegen kaum mehr Nahrungsmittel in die Stadt liefere. ${ }^{63}$

\section{Die verlorenen Urkunden und Briefe über das antihussitische Handelsverbot}

Glaubt man den eben diskutierten Nachrichten, müssen im Budweis der 1420er und 30er Jahre Unmengen von „Zetteln“ im Umlauf gewesen sein, die der obrigkeitlichen Kontrolle des Warenverkehrs dienten. Meines Wissens hat sich allerdings nicht ein einziger dieser Förderbriefe im dortigen Archiv erhalten. Selbst im Stadtarchiv Eger, das als eines der besterhaltenen Stadtarchive Böhmens gilt, sind mir aus der Zeit des ersten Hussitenkrieges lediglich die drei bereits genannten Stücke für Pilsner Bürger bekannt. ${ }^{64}$ Sucht man nach dem Grund für diese „Anomalie“ stellt man fest, dass es ein viertes Schreiben der Pilsner Ratsherren an die Egerer gibt, das in engem zeitlichen und inhaltlichen Zusammenhang mit den drei erhaltenen Förderbriefen steht. ${ }^{65}$ Dieses Schreiben betrifft mehrere Vorfälle, bei denen Güter Pilsner Kaufleute in Eger beschlagnahmt worden waren, und um deren Freigabe die Pilsner ihre Egerer Amtskollegen ersuchten. Diese Beschlagnahmen sorgten mutmaßlich für Unruhe bei geschäftlich in Eger aktiven Pilsnern. Es ist daher durchaus denkbar, dass die überlieferten Förderbriefe gar nicht auf Vorschriften des Egerer Rates zurückgingen. Möglicherweise ließen die betreffenden Pilsner Händler sich vielmehr vorsorglich für die Reise nach Eger Förderbriefe ausstellen, um sich auf diese Weise gegen ähnliches Unbill, wie es ihren Mitbürgern widerfahren war, abzusichern. Eben dieser Zusammenhang ist weiters vermutlich auch dafür verantwortlich, dass von all den damals kursierenden „Zetteln“ und „Briefen“ gerade die genannten drei Stück erhalten geblieben sind.

Begleiter eines aus dem katholischen Ungarisch Hradisch [Uherské Hradiště] kommenden Warenzuges durch Olmützer Söldner im Frühling 1425 ergaben.

62 Orig. SOkA České Budějovice, AM České Budějovice, Chronologische Reihe, Sg. 1426/1, Albrecht V. an Leopold von Kraig, 1426, Juni 8, Wien. Das Stück trägt den bezeichnenden Dorsalvermerk littera de cedulis.

63 Ebd.: daz menicleich und sunder unser burger zu dem Budweis vast damit beswert sein, wan die leut auf dem land gesessen dester ungerner narung in die stat fürent, daraus uns und der stat scheden kömen möchten.

64 Siehe oben, Anm. 45.

65 Orig. SOkA Cheb, AM Cheb, Kart. 504, Fasz. 695, Nr. A-2985/4; Listář královského města Plzně a druhdy poddaných osad [Urkundenbuch der königlichen Stadt Pilsen sowie der einst untertänigen Ortschaften]. 1: 1300-1450. Ed. J. Strnad. Plzeň 1891, S. 321-322, Nr. 299, der Pilsner Rat an den Rat der Stadt Eger, 1428, September 29, Pilsen. 
Die eben skizzierten Umstände sind typisch für die geringe Überlieferungschance nicht nur von Förderbriefen, sondern auch von vielen anderen Typen von im Krieg entstandenen Gebrauchsschriftstücken. Der weitaus größte Teil des mit dem antihussitischen Handelsverbot in Zusammenhang stehenden Schriftgutes ist heute verloren, selbst wenn es sich um obrigkeitliche Befehle handelte, die das Handelsverbot einschärften. So hat sich etwa in den bereits erwähnten, an Briefen und Mandaten außergewöhnlich reichen Egerer Beständen kein einziges Mandat erhalten, das das antihussitische Handelsverbot einschärft. Dessen ungeachtet handelte es sich bei solchen Mandaten zweifellos um Schriftstücke, die für eine weite Verbreitung gedacht waren. Für diese Annahme sprechen nicht nur die Art der Ausfertigung als offene Briefe und die oben im Zusammenhang mit den päpstlichen Kreuzzugsinitiativen bereits hervorgehobene propagandistisch-rhetorische Qualität dieser Urkunden. Wie bereits angeklungen ist, gibt es darüber hinaus Hinweise, dass es sich bei den überlieferten Textzeugnissen in einigen Fällen lediglich um die Reste größerer Serien von Urkunden handelt. Hingewiesen sei hier zum einen auf die bereits erwähnten beiden parallelen Mandate Sigismund an die Adresse der Städte Breslau und Görlitz vom April $1431 .{ }^{66}$ Der König hatte damals versucht, angesichts des Scheiterns der vorangegangenen Kreuzzüge anstelle eines weiteren großangelegten Feldzuges gegen die Hussiten lieber einen „täglichen Krieg“, d. h. einen niederschwelligen, jedoch kontinuierlichen Grenzkrieg zu organisieren. Gleichzeitig behielt er auch eine Lösung der Hussitenfrage am Verhandlungstisch im Blick. Der damalige päpstliche Legat, Kardinal Giuliano Cesarini, hingegen betrieb auf einer Reichsversammlung in Nürnberg einen neuen Kreuzzug. Seine Initiative traf sich mit den Bedenken der Reichsstände bezüglich der kaum absehbaren Kosten des von Sigismund geforderten „täglichen Krieges“. Der König war daraufhin gezwungen, wieder auf eine dezidiert militärische Politik einzuschwenken und sich möglichst öffentlichkeitswirksam als aktiver Kämpfer gegen die Hussiten zu positionieren. ${ }^{67}$ Unter diesem Blickwinkel scheint es durchaus möglich, dass die königliche Kanzlei im April 1431 nicht allein auf Wünsche der Breslauer Empfänger reagierte, ${ }^{68}$ sondern parallel zu den Mandaten an Breslau und Görlitz noch weitere vergleichbare Schriftstücke ausstellte, die sich allerdings nicht erhalten haben.

Noch deutlicher als an diesem Beispiel wird die gezielte Verbreitung von Urkunden über das antihussitische Handelsverbot anhand von vier Urkunden fassbar, die am 16. bzw. 17. Mai 1424 im ungarischen Blindenburg ausgestellt wurden. Wie bereits erwähnt, wandte Sigismund sich damals bezüglich der antihussitischen Beschlüsse des Konzils von Pavia-Siena an die Stadt Regensburg und alle Städte in Schlesien. ${ }^{69}$ Parallel dazu verfasste der damalige päpstliche Legat, Kardinal Branda da Castiglione, zwei Schreiben,

66 Vgl. oben, bes. Anm. 15 und 19.

67 Zur Ereignisgeschichte vgl. Wefers, Sabine: Das politische System Kaiser Sigmunds. Beiträge zur Sozial- und Verfassungsgeschichte des Alten Reiches 10. Stuttgart 1989, S. 174-176; Hoensch, Jörg K.: Kaiser Sigismund. Herrscher an der Schwelle zur Neuzeit 1368-1437. München 1996, S. 363-366; Studt, B.: Martin V., S. 687-691; Spengler, Hartmut: Der Nürnberger Tag von 1431 und der Beschluss des letzten Hussitenfeldzuges. Mitteilungen des Vereins für Geschichte der Stadt Nürnberg 101, 2014, S. 39-78.

68 Siehe oben, bes. Anm. 27.

69 Vgl. oben, Anm. 13 und 16. 
mit denen er den Bischöfen von Regensburg und Meißen selbige Beschlüsse mitteilte. ${ }^{70}$ Bei den vier bislang bekannten Urkunden handelt es sich vermutlich ebenso wie im April 1431 lediglich um die Reste einer größeren Serie, die zur systematischen Verbreitung in den Nachbarländern Böhmens gedacht war. Dafür spricht zum einen, dass die erhaltenen Schreiben in unterschiedliche Regionen gesandt wurden, die zusammengenommen das Bild einer planvollen Abdeckung der böhmischen Nachbarländer von Bayern über Meißen nach Schlesien evozieren. ${ }^{71}$ Zum anderen befand Sigismund sich im Frühling 1424 angesichts der Herausforderung durch die im sogenannten Binger Kurverein zusammengeschlossenen Kurfürsten, die ihm Untätigkeit in der böhmischen Frage vorwarfen, in einer noch brisanteren politischen Lage, als sieben Jahre später in Nürnberg. ${ }^{72}$ Es scheint daher wahrscheinlich, dass er schon damals auf die kommunikativ-propagandistische Wirkung von Urkunden über das antihussitische Handelsverbot zurückgriff. ${ }^{73}$ Vor allem aber wissen wir aufgrund des oben erörterten Schreibens des Nürnberger an den Regensburger Rat vom Juni 1424, dass zumindest Sigismunds Mandat ausdrücklich für die weiträumige Publikation vorgesehen war. ${ }^{74}$ Hinsichtlich der hier im Mittelpunkt stehenden Frage nach der Überlieferungschance von Urkunden und Briefen über das antihussitische Handelsverbot ist schließlich bezeichnend, dass drei der vier eben genannten Stücke lediglich abschriftlich überliefert sind, davon gleich zwei in der „Hussitenchronik“ des Andreas von Regensburg. ${ }^{75}$ Dieses Beispiel macht auch deutlich, dass die ungleichmäßige Überlieferungslage das Bild, das wir vom antihussitischen Handelsverbot haben, nicht unwesentlich verzerren dürfte. Die auffällige Prominenz von Stadt und Diözese Regensburg in den einschlägigen Quellen etwa liegt wohl nicht allein in der geografischen Lage und der traditionellen Rolle Regensburgs im Böhmenhandel begründet. ${ }^{76}$ Ebenso großen Anteil daran hat mutmaßlich die relativ gute urkundliche Überlieferung für Hochstift und Stadt Regensburg, insbesondere aber das Sammlungsinteresse des Andreas von Regensburg. Dessen historiografische Werke enthalten etliche

70 Palacký, F.: Urkundliche Beiträge, 1, S. 336-338, Nr. 293 und Studt, B.: Martin V., S. 536, Anm. 258, Branda da Castiglione an den Bischof von Regensburg/Meißen, 1424, Mai 16, Blindenburg.

71 Vgl. in diesem Zusammenhang auch die Vorschriften Branda da Castigliones hinsichtlich der Publikation der Sieneser Beschlüsse in allen Kirchen der von ihm angesprochenen Diözesen, insbesondere in denjenigen vicinis et propinquis Bohemie et Morauie, Palacký, F.: Urkundliche Beiträge, 1, S. 337. Weder die Diözese Regensburg noch Meißen grenzen an Mähren, was andeuten könnte, dass es noch weitere Empfänger gab, deren Bistümer sehr wohl eine Grenze mit Mähren besaßen. Zur Frage der Publikation vgl. auch im Folgenden.

72 Zur Ereignisgeschichte vgl. Wefers, S.: System, S. 120-122; Hoensch, J.: Sigismund, S. 318-322.

$73 \mathrm{Zu}$ dieser gezielten Indienstnahme des antihussitischen Handelsverbotes für propagandistische Zwecke vgl. Kaar, A.: Neue Mittel, S. 234, 241-242 und vor allem dies.: Wirtschaft, S. 269-280, bes. S. 276-278 zu den hier behandelten Ereignissen.

74 Vgl. oben, Anm. 17.

75 Dabei handelt es sich um die beiden Mandate an die Stadt Regensburg bzw. den Bischof von Regensburg, siehe oben, Anm. 13 und 70.

76 Vgl. dazu lediglich Graus, František: Die Handelsbeziehungen Böhmens zu Deutschland und Österreich im 14. und zu Beginn des 15. Jahrhunderts. Eine Skizze. Historica 2, 1960, S. 77-110, hier S. 96-100. Allerdings verlor der Regensburger Böhmenhandel seit dem späteren 14. Jahrhundert zugunsten Nürnbergs an Bedeutung. 
Urkunden, deren Originale sich offenbar trotz der vergleichsweise dichten urkundlichen Überlieferung nicht erhalten haben. So konnten bisher weder das bei František Palacký nach Andreas' Chronik gedruckte Schreiben Branda da Castigliones, noch das nach derselben Überlieferung gedruckte Mandat Sigismunds im Original aufgefunden werden.

Andreas“ „Hussitenchronik“ hat kein Parallelstück aus einer anderen Stadt oder einem anderen Kloster, welches eventuelle Lücken der dortigen Überlieferung ausgleichen könnte. Für eine Rekonstruktion der verlorenen Urkunden und Briefe über das antihussitische Handelsverbot ist man daher auf vereinzelte Nachrichten vor allem aus städtischen Korrespondenzen angewiesen. So informiert uns etwa ein Brief des Olmützer Stadtrates an Hauptmann und Rat der mährischen Stadt Ungarisch Hradisch vom Frühling 1425 über die Publikation päpstlicher litterae über das Handelsverbot in Olmütz ${ }^{77}$ sowie die parallele Einschärfung des Verbotes durch Herzog Albrecht V. ${ }^{78}$ Während das päpstliche Schreiben dank der kurialen Überlieferung bekannt ist, scheint sich die schriftliche Fassung von Albrechts Befehl - so es eine solche gab - hingegen nicht erhalten zu haben. ${ }^{79}$ Ein einschlägiges Mandat Sigismunds vom Winter 1421 wiederum kennen wir nur aus den Korrespondenzen des Salzburger Rates. ${ }^{80}$ Ein zeitgenössisches Briefbuch enthält einen Brief der Salzburger Ratsherren an Johann von Borek (Jan von Work $){ }^{81}$ einen diener Sigismunds, der einen gewissen Oswald vor dem Salzburger Rat we-

77 SOkA Olomouc, Olmützer Briefbuch, F. 163r; Palacký, F.: Urkundliche Beiträge, 1, S. 391-392, der Rat von Olmütz an Hauptmann und Rat von Ungarisch Hradisch, 1425, April 26, Olmütz: [Vobis] significamus, quod auctoritate literarum apostolicarum de recenti noviter directarum nobis juxta totam diocesim Olomucensem extat seriosissime mandatum, quatenus nullus audeat hereticis sub gravissima excommunicationis pena ... vinum, species, victualia, merces nec aliquid talium apportare; quinimo universi, qui ispsis hereticis solum favorem aut complacentiam seu fomentum prestant, noverint se suprascriptum anathema incursuros. Vermutlich handelt es sich bei den genannten päpstlichen litterae um Eršil, J.: Acta, 2, S. 515-516, Nr. 1274, Martin V. an die Bischöfe von Regensburg, Passau, Meißen, Bamberg und Olmütz (!), 1424, November 24, Rom.

78 SOkA Olomouc, Olmützer Briefbuch, F. 163r: Similiter etiam illustris dux Austrie et marchio Moravie ... nobis districtius inhibendo mandavit, ut omnes, qui ipsis Hussitis adducere conarentur, persequi debeamus, quos etiam omni sine gratia corrigere wellet (!) et punire.

79 Zumindest verzeichnet das in Vorbereitung befindliche Supplement zu J. F. Böhmer, Regesta Imperii XII. Albrecht II. (1438-1439). Regesten der Urkunden Herzog Albrechts V. vor seiner Wahl zum römischen König. Ed. P. Elbel, in dem künftig die Urkunden Albrechts V. aus den Archiven und Bibliotheken Böhmens und Mährens publiziert werden sollen, keine entsprechende Urkunde Albrechts. Vgl. dazu die Projektbeschreibung „Herrschaft im Angesicht hussitischer Wagenburgen. Der österreichische Herzog und römische König Albrecht V. (II.) in den Böhmischen Ländern (1421-1439)“, FWF-Projekt (2010-2016), Institut für Mittelalterforschung der ÖAW, https://www.oeaw.ac.at/imafo/forschung/editionsunternehmen-quellenforschungmir/regesta-imperii-wien/projekte/albrecht-ii/ (Zugriff 4. Februar 2019). Ich danke Petr Elbel für die Zurverfügungstellung noch unveröffentlichter Materialien.

80 Stadtarchiv Salzburg (= StA Salzburg), Buchförmige Archivalien Nr. 6, sogenanntes Sandbriefbuch (= Sandbriefbuch), Pag. 248, Nr. 399, der Salzburger Rat an Johann von Borek, 1421, März 31, Salzburg. Ich danke Ondřej Vodička für diesen Hinweis.

81 Der Genannte konnte bisher nicht identifiziert werden. In Böhmen gibt es eine Reihe von Ortschaften mit diesem Namen. Möglicherweise stammte Johann aus dem westböhmischen Borek (südöstlich von Karlsbad [Karlovy Vary]), das auch unter der Namensform „Worka“ belegt ist, vgl. Profous, Antonín: Místní jména v Čechách, jejich vznik, piơodni význam a změny [Ortsnamen in Böhmen, ihre Entstehung, ihre ursprüngliche Bedeutung und ihr Wandel]. Praha 1947, 1, S. 121, Nr. 25. Im August 1420 verpflichtete Sigismund sich jedenfalls, einem gewissen Wenzel von Borek ausständigen Sold zu bezahlen, vgl. RI XI, 1, 
gen angeblichen Hussitenhandels angeklagt hatte. Diesem Brief ist eine eidesstattliche Erklärung des Beklagten beigegeben, er habe nicht mit den Hussiten Handel getrieben. ${ }^{82}$ Das Schreiben enthält eine Vielzahl faszinierender Details zum zeitgenössischen Kriegsalltag, die bereits an anderer Stelle näher ausgewertet worden sind.$^{83} \mathrm{Im}$ vorliegenden Zusammenhang ist von Interesse, dass Oswald in seiner Aussage en passant erklärt, er habe keinen Handel mit den Hussiten treiben können, da es ein königliches usschreiben, d. h. einen schriftlichen Befehl - wohl in Form eines offenen Briefes - an den Erzbischof von Salzburg gegeben habe, mit dem dieser aufgefordert worden war, seinen Untertanen jegliche wirtschaftliche Beziehungen mit den Hussiten zu untersagen. ${ }^{84}$ Bei dieser beiläufigen Bemerkung handelt es sich - nach heutigem Erkenntnisstand - um den frühesten Beleg dafür, dass König Sigismund das antihussitische Handelsverbot gezielt in seinem Herrschaftsbereich publizieren ließ. So wie andere diesbezügliche Nachrichten auch ist diese Information lediglich indirekt auf uns gekommen, was noch einmal das Auseinanderklaffen zwischen einstmals vorhandenen und heute noch existierenden Urkunden und Briefen über das antihussitische Handelsverbot illustriert. ${ }^{85}$

\section{Die Publikation der Urkunden und Briefe über das antihussitische Handelsverbot}

In den beiden vorangegangenen Abschnitten ist die Frage nach der Publikation und Rezeption des antihussitischen Handelsverbotes bereits mehrfach angeklungen. Im letzten Abschnitt soll nun etwas systematischer auf dieses Thema eingegangen werden. Dazu werden die normativen Vorstellungen der Propagatoren des Verbotes zusammengestellt mit jenen Nachrichten, die wir über die praktische Umsetzung dieser Vorgaben besitzen.

Wie andernorts bereits ausführlich dargelegt, entsprang das antihussitische Handelsverbot einer langen Tradition religiös fundierter Verbote von wirtschaftlichen Kontakten zwischen Christen und Nicht-Christen. ${ }^{86}$ Entsprechend überrascht es nicht, dass sowohl die geistliche, als auch die weltliche Macht auf etablierte Kommunikationskanäle

S. 296, Nr. 4200, Sigismund für Wenzel von Borek und Hanuš von Skalka, 1420, August 10, Kuttenberg [Kutná Hora]. Vgl. auch die übrigen Registereinträge zu „Borek“ in RI XI. Ich danke Stanislav Bárta, Petr Elbel und Robert Novotný für Hinweise.

82 StA Salzburg, Sandbriefbuch, Pag. 248, Nr. 398, eidesstattliche Aussage eines nicht weiter identifizierbaren Oswald, vor 1421, März 31, Salzburg.

83 Vgl. Kaar, A.: Wirtschaft, passim, v. a. S. 157-158.

84 StA Salzburg, Sandbriefbuch, Pag. 248, Nr. 398: von des usschreibens wegen, so dann [der] allerdurichlawchtigist furst, kunig Sigmundt etc. dem hochwirdigen fursten, meinem genädigen herren von Salczburg etc. verschriben und verpieten hat haissen, das chainer der seinen soleichen gut [= Waffen] in Pechaim nicht furen sol.

85 Siehe oben, Anm. 18, sowie StAN, BB, Nr. 5, F. 214r-215r; Palacký, F.: Urkundliche Beiträge, 1, S. 189-190, Nr. 176, der Nürnberger Rat an Sigismund/Albrecht von Colditz, 1422, April 17, Nürnberg, wo von einem schriftlichen Befehl Sigismunds an den Nürnberger Rat das antihussitische Handelsverbot betreffend die Rede ist. Vgl. dazu auch im Folgenden.

86 Vgl. Kaar, A.: Wirtschaft, passim, v. a. S. 27-41, basierend auf der grundlegenden Arbeit von Stantchev, Stefan K.: Spiritual rationality. Papal embargo as cultural practice. Oxford 2014. 
zurückgreifen konnten, um das Handelsverbot gegen die böhmischen Hussiten zu propagieren. Seitens der Kurie ist hier zunächst die sogenannte Abendmahlbulle zu nennen. Bei diesen jeweils am Gründonnerstag zunächst in Rom verkündeten, und dann in den einzelnen Diözesen zu publizierenden Bullen handelte es sich um eine Sammlung päpstlicher Generalsentenzen, mit denen ipso facto-Exkommunikationen für eine stetig wachsende Zahl von Vergehen gegen die Christenheit im Allgemeinen und gegen das Papsttum im Speziellen publiziert wurden. ${ }^{87}$ Die Exkommunikation all jener, die mit Feinden der Christenheit Handel betrieben, wurde bereits im 13. Jahrhundert Teil der in coena Domini-Bullen. ${ }^{88}$ Da unter dem Eindruck zeitgenössischer Ereignisse aber stets auch konkrete Spezialsentenzen in die Abendmahlbulle aufgenommen wurden, überrascht es nicht, dass unter Martin V. und dessen Nachfolger, Papst Eugen IV., die hussitische „Häresie“ Eingang in das Formular fand. Alle, die den Hussiten Waren zuführten oder sie anderweitig unterstützten, wurden ausdrücklich exkommuniziert, ${ }^{89}$ auch wenn der Umgang mit Hussiten ohnehin automatisch unter das kirchliche Kontaktverbot mit Häretikern fiel.

Wie wir im Vorangehenden gesehen haben, stellte die Kurie neben der Abendmahlbulle noch eine Reihe weiterer litterae über das antihussitische Handelsverbot aus. Über die Art und Weise, wie diese Schreiben konkret publiziert werden sollten, informieren uns unter anderem die oben erwähnten Schreiben Branda da Castigliones vom Frühling 1424. ${ }^{90}$ Der Legat forderte die Bischöfe von Regensburg und Meißen darin auf, die Beschlüsse des Konzils von Pavia-Siena jeden Sonn- und Feiertag in sämtlichen Kollegiats- und Pfarrkirchen ihrer Diözesen verkünden zu lassen, insbesondere in den grenznahen Pfarreien. ${ }^{91}$ Vergleichbare, wenn auch noch ausführlichere Bestimmungen enthält auch die ebenfalls bereits erwähnte Bulle Martins V. vom Jänner $1431 .{ }^{92}$ Der Papst forderte darin in enger Anlehnung an die antihäretischen Bestimmungen des Kirchenrechts die öffentliche Denunziation von Schwarzhändlern an Sonn- und Feiertagen als Interdizierte, Exkommunizierte und Glaubensfeinde, und ordnete die Publikation der Bulle durch alle zuständigen Bischöfe und Erzbischöfe sowohl in Böhmen selbst als auch

87 Zur Textgeschichte der Bulle in coena Domini vgl. Jaser, Christian: Ecclesia maledicens. Rituelle und zeremonielle Exkommunikationsformen im Mittelalter. Spätmittelalter - Humanismus - Reformation 75, Tübingen 2013, S. 382-404.

88 Ebd., S. 382-383; Stantchev, St.: Spiritual rationality, S. 101-104, 123-124, 164-165.

89 Vgl. Göller, Emil: Die päpstliche Pönitentiarie von ihrem Ursprung bis zu ihrer Umgestaltung unter Pius V. 1-1: Die päpstliche Pönitentiarie bis Eugen IV. Darstellung. Bibliothek des Königlich Preussischen Historischen Instituts in Rom 3, Rom 1907, S. 263-264 (Abendmahlbulle Martins V., 1426, Rom); ausführlich ebd., S. 270-271, Abendmahlbulle Eugens IV., 1434, April 24, Rom. Laut Göller könnte das Formular der letzteren Bulle bereits im Jahr 1433 Verwendung gefunden haben; es wurde bis in die Zeit Pauls II. beibehalten.

90 Siehe oben, Anm. 70.

91 Palacký, F.: Urkundliche Beiträge, 1, S. 336-338, Nr. 293, hier 337, 1424, Mai 16, Blindenburg: mandantes vobis ..., ut in ecclesia kathedrali et aliis collegiis et parochialibus ecclesiis ciuitatis et diocesis vestrarum, presertim vicinis et propinquis Bohemie et Morauie, singulis diebus dominicis et sollempnitatibus, cum populus ad diuina audienda conuenerit, predictum decretum publice promulgetis seu promulgari faciati.

92 Theiner, A.: Monumenta, S. 209, Nr. 367, Martin V. an alle Gläubigen, 1431, Jänner 9, Rom. Siehe oben, Anm. 8. 
in den umliegenden Ländern, sowie deren Veröffentlichung in Rom an, damit niemand sich darauf berufen konnte, ihm seien die in der Bulle zusammengestellten Anordnungen über das Handelsverbot unbekannt gewesen. ${ }^{93}$

Wie oben bereits erwähnt wurde, gehörte diese Bulle zur „Ausstattung“ des päpstlichen Legaten Giuliano Cesarini für dessen Reise ins Reich. Zusammen mit den Briefen Branda da Castigliones illustriert dies die bedeutende Rolle der päpstlichen Legaten für die Propagierung der antihussitischen Politik der Kurie. Was Birgit Studt für die Legaten Martins V. herausgearbeitet hat, ${ }^{94}$ trifft in wohl ebenso großem Maße für die Zeit des zweiten Hussitenkrieges gegen Georg von Podiebrad zu, als mehrere Legaten parallel den Papst vor Ort in Mitteleuropa vertraten..$^{95}$ Auch deren Tätigkeit umfasste nachweislich die Vervielfältigung und Publikation päpstlicher litterae über das Handelsverbot. Die lateinische Version der Chronik des Breslauer Stadtschreibers Peter Eschenloer etwa überliefert die Abschrift einer umfänglichen diesbezüglichen Bulle Papst Pauls II. vom April 1468, die der päpstliche Legat Lorenzo Roverella in Schlesien veröffentlichen und durch Transumpte vervielfältigen und weiterversenden hatte lassen ${ }^{96}$ so wie es davor und danach mutmaßlich auch mit vielen anderen Urkunden über das antihussitische Handelsverbot geschah. ${ }^{97}$

Parallel zu diesen kurialen Kommunikationskanälen wurde das antihussitische Handelsverbot auch über weltliche Kanäle verbreitet. Als der polnische König Wladislaw Jagiello im April 1424 das bereits erwähnte Edikt von Welun promulgierte, befahl er allen seinen weltlichen Amtsträgern, dasselbe in allen Städten, Märkten und Dörfern et aliis quibuscunque locis publicis et privatis, insbesondere dort, wo Recht gesprochen wurde und wo sich große Menschenmengen versammelten, ausrufen zu lassen. ${ }^{98}$ Andreas von Regensburg schildert zur selben Zeit eine solche öffentliche Verlautbarung in Regensburg, wohl durch einen offiziellen städtischen Ausrufer. ${ }^{99}$ Wie aus diesem Beispiel deutlich wird,

93 Vgl. die detaillierte Analyse dieses Dokuments bei Kaar, A.: Wirtschaft, S. 38-41.

94 Studt, B.: Martin V., passim, bes. S. 431-474.

95 Vgl. zu diesen zuletzt Kalous, Antonín: Late Medieval Papal Legation. Between the Councils and the Reformation. Roma 2017, S. 155-157.

96 Vgl. den Zusatz Eschenloers zu Politische Correspondenz Breslaus im Zeitalter König Georgs von Podiebrad. Zugleich als urkundliche Belege zu Eschenloers Historia Wratislaviensis 2, ed. H. Markgraf. Scriptores rerum Silesiacarum 9. Breslau 1874, S. 265-267, Nr. 392, hier S. 267, Paul II. an alle Gläubigen, 1468, April 20, Rom: Presentata fuit domino legato in primis diebus Julii et ... sub transsumpcione plurificata missaque hincinde. Die Bulle enthält die ausdrückliche Aufforderung zur Vervielfältigung mittels Transumpten.

97 Ein Textvergleich legt etwa nahe, dass der Olmützer Kanzlei im Frühling 1425 tatsächlich eine schriftliche Version jener päpstlichen litterae vorlag, auf welche die Ratsherren sich in ihrem Brief an Hauptmann und Rat von Ungarisch Hradisch bezogen, siehe oben, Anm. 78.

98 Siehe oben, Anm. 29, hier S. 332-333: Quocirca vobis omnibus et singulis capitaneis, burgraviis, procuratoribus, magistris civium et aliis regni nostri officialibus et subditis, ad quos praesentes pervenerint, mandamus, quatenus praesens nostrum edictum firmiter custodire debeatis, et ubilibet in civitatibus, oppidis, villis et aliis quibuscunque locis publicis et privatis, et specialiter ubi tractabuntur judicia, et ubicunque contigerit aliquam hominum multitudinem confluere, palam et vocibus praeconum faciatis proclamare.

99 Andreas von Regensburg, Sämtliche Werke, ed. G. Leidinger. Quellen und Erörterungen zur bayerischen und deutschen Geschichte N. F. 1. München 1903, S. 314, zu 1424, Jänner 16: Item anno domini 1424 ... in 
waren es vor allem die städtischen Räte, die Befehle hinsichtlich des antihussitischen Handelsverbotes verbreiteten, sowohl horizontal zwischen den einzelnen Städten, ${ }^{100}$ als auch vertikal von der Ebene der Kurie oder des Stadtherrn auf die Ebene der einzelnen Kaufleute. Aus einem Brief des Nürnberger Rates an König Sigismund vom April 1422 erfahren wir etwa, dass dieser den Stadtrat nach einigen verdächtigen Vorkommnissen aufgefordert hatte, seinen Bürgern zu verbieten, den Hussiten irgendwelche Waren zu verkaufen. ${ }^{101}$ Die Nürnberger beeilten sich daraufhin, dem König zu versichern, sie seien derselben ewr hochwürdigkeit begerung gern willig und gehorsam gewesen und haben das den unsern also zu wissen getan und verpotten. Aus der Zeit des zweiten Hussitenkrieges hat sich über einen vergleichbaren Vorgang auch tatsächlich ein Vermerk in einem Amtsbuch erhalten, dem zufolge der Rat die Angehörigen der städtischen Elite dazu angehalten hatte, den Handel mit Böhmen einzustellen, da er sonst dazu genötigt sei, sie an leibe und gut zu strafen, was auch für alle anderen Einwohner der Stadt gelte. ${ }^{102}$ Ähnliches spielte sich 1471 auch in Regensburg ab. ${ }^{103}$

Wie aus dem Vorangehenden deutlich geworden ist, wurden die päpstlichen litterae und königlichen Mandate über das antihussitische Handelsverbot regelmäßig öffentlich publiziert und der Allgemeinheit ins Bewusstsein gerufen. Es fällt daher einigermaßen schwer, einem Nürnberger Bürger Glauben zu schenken, der im Winter 1428 behauptete, das Verbot, Harnische nach Böhmen zu liefern, sei ihm unbekannt gewesen. ${ }^{104}$ Diese normativen Schriftstücke waren aber nicht der einzige Weg, auf dem das Handelsverbot seinen

quodam loco Ratisponensis diocesis in loco, quo solent publicari plebescita, per preconem loci eiusdem est publicatum, quod nemo aliquem Bohemum sive de Bohemia sive emendo sive vendendo seu quovis alio modo contrastando debeat ledere sub amissione rerum et corporis. Hoc tamen mandatum paucis emergentibus diebus postea fuit revocatum [= nochmals ausrufen]. Die Regensburger Ratsherren ließen damals wohl das im November 1423 beschlossene antihussitische Dekret des Konzils von Pavia-Siena verlautbaren, immerhin vier Monate bevor Sigismund sie offiziell dazu aufforderte. Dies zeigt die weite Rezeption dieses Dekrets, welches auch in anderen einschlägigen Quellen nachhallt. Vgl. dazu Kaar, A.: Wirtschaft, passim, bes. S. 107-174.

100 Vgl. die oben genannten Beispiele, siehe oben, Anm. 6, 17 und 18.

101 Siehe oben, Anm. 85.

102 StAN, Reichsstadt Nürnberg, Ratsbuch 1c, F. 162v, Abschnitt 4, Protokoll zur Sitzung von 1468, September 26, Nürnberg: Item den genanten ist gesagt, das sie, noch ander buerger oder inwonner dieser stat, gen Beheim nit arbeiten noch handeln haben solen, oder ein rate werde sie an leibe und gut stroffen. Die Genannten bildeten den Größeren Rat, aus dem sich der die politischen Geschäfte leitende sogenannte Innere Rat rekrutierte, vgl. Bauernfeind, Walter: Artikel Genanntenkollegium. In: Stadtlexikon Nürnberg, hg vom Stadtarchiv Nürnberg, online unter http://online-service2.nuernberg.de/stadtarchiv/zeig.FAU?sid=BF1A92FC8\&d $\mathrm{m}=4$ \&ind=1\&ipos=Genanntenkollegium (Zugriff 7. Februar 2019).

103 Stadt Regensburgische Jahrbuecher vom Jahre 1430 bis zum Jahre 1496. Aus der Urquelle, den Koeniglichen Archiven und Registraturen zu Regensburg. Ed. C. Th. Gemeiner. Regensburgische Chronik 3. Regensburg 1821, S. 475, Anm. 926, 1471, Jänner 7, Regensburg: Mein Herren haben großen Fleiß fuerkehrt ..., daß nichts durch ihr Buerger mit Baennigen [= Gebannten] gehandelt werden solle, und haben zugesagt ihren Cramern und Kaufleuten und andern ernstlich geboten, mit Baennigen nichts zu handeln ... Sie haben auch ihren geschwornen Ladern [= wohl die Angehörigen des zünftigen Transportgewerbes] untersagt, ihr Treu und Geluebd an Eidesstatt genommen, alles, das sie laden, alle Tage anzusagen, damit man allen Handel aufrichtig thue und verantworten moege.

104 StAN, BB Nr. 8, F. 93r, der Nürnberger Rat an Johann von Pfalz-Neumarkt/den Landschreiber zu Sulzbach, 1428, Dezember 2, Nürnberg. 
Weg in den Alltag der Hussitenkriege fand; auch waren, wie wir gesehen haben, Mandate, die wirtschaftlichen Umgang mit den Hussiten verboten, bei weitem nicht die einzigen Schriftstücke, die im Zusammenhang mit dem antihussitischen Handelsverbot entstanden.

Zum Schluss sei hier daher noch ein letztes Beispiel aus diesem reichen Fundus verschiedenartiger Urkunden und Briefe herausgegriffen. Dieses illustriert einerseits, wie tief die Idee des antihussitischen Handelsverbotes im Bewusstsein der Bevölkerung der böhmischen Nachbarländer verankert war. Andererseits schlägt es noch einmal den Bogen zurück zur Frage nach dem „Sitz im Leben“ der hier untersuchten Schriftstücke und besonders nach dem Ausmaß der vom antihussitischen Handelsverbot hervorgerufenen pragmatischen Schriftproduktion.

\section{Schlussbetrachtungen}

Am 16. Juni 1426 erlitten sächsisch-meißnische Truppen bei Aussig an der Elbe [Ústí nad Labem] eine vernichtende Niederlage gegen die verbündeten hussitischen Heere. ${ }^{105}$ Der hussitische Sieg war ein schwerer Schock für die katholische Seite und fand in zahlreichen zeitgenössischen Quellen seinen Niederschlag, darunter auch in der nach 1434 entstandenen Fortsetzung der Chronik des Dietrich Engelhus durch den damaligen Provinzial der Franziskanerminoriten in Sachsen, Matthias Döring. ${ }^{106}$ Darin schildert der Autor im Anschluss an den Bericht über die eigentliche Schlacht die große Menge von Waffen, Wagen, Lebensmitteln und Pferden, die die siegreichen Hussiten erbeutet hatten. ${ }^{107}$ Die Beute sei so groß gewesen, dass die hussitischen Hauptleute sich angeblich bemüßigt fühlten, dem sächsischen Herzog, Friedrich I. von Sachsen, in einem ironischen Brief dafür zu danken. In dem von Döring zitierten Brief weisen die Absender Friedrich dabei sarkastisch auf die Tatsache hin, dass er ab sofort exkommuniziert sei, da der Papst doch alle exkommuniziere, die die Hussiten mit Lebensmitteln und sonstigen Hilfsleistungen unterstützten, wie der Herzog es eben so großzügig getan hätte. ${ }^{108}$

Es ist höchst unwahrscheinlich, dass der Überlieferung bei Döring ein authentischer Brief zu Grunde liegt. ${ }^{109}$ Viel eher handelt es sich um eine literarische Fiktion des Chronisten, der damit den Siegern unchristlichen Hochmut unterstellt und gleichzeitig die

105 Zur Ereignisgeschichte vgl. lediglich Šmahel, František: Die Hussitische Revolution 1-3. Schriften der MGH 43. Hannover 2002, 2, S. 1382-1392.

106 Zum Autor vgl. Zur Geschichte der Schlacht bei Aussig. Ed. H. Ermisch. Neues Archiv für Sächsische Geschichte und Altertumskunde 47, 1926, S. 5-45, hier S. 29-30; Artikel Döring, Matthias. In: Repertorium Fontium. Geschichtsquellen des deutschen Mittelalters Hg. von der Bayerischen Akademie der Wissenschaften, online unter http://www.geschichtsquellen.de/repPers_100964664.html (Zugriff 15. Februar 2019).

107 Geschichte, ed. Ermisch, S. 43-44, Nr. XIV, hier S. 44.

108 Ebd.: Et fertur eos [Bohemos] duci Saxonum scripsisse: ,Si excommunicacio pape tui ligat, qui excommunicat omnes adducentes nobis victualia et impercientes auxilia nobis. tunc tu es excommunitus, quia misisti nobis, tunc tu es excommunicatus, quod misisti nobis cibos in copia, equos, currus et arma. Vale.

109 So auch die Einschätzung bei Čornej, Petr: Bitva před Ústím nad Labem ve starši české a německé tradici [Die Schlacht bei Aussig in der älteren tschechischen und deutschen Tradition]. Acta Universitatis Carolinae. Philosophica et Historica 5, 1995. Studia historica 43. Problémy dějin historiografie 7, 1999, S. 9-64, hier S. 54. 
Schmach der Verlierer unterstreicht. Diese Fiktion belegt jedoch, dass das Prinzip des antihussitischen Handelsverbotes - Hussitenhändler verfallen als Unterstützer von Häretikern der Exkommunikation - für den Autor so selbstverständlich war, dass er der hussitischen Seite unterstellen konnte, sich dieser Tatsache zu propagandistischen Zwecken zu bedienen. Im Zusammenhang mit dem Thema des vorliegenden Bandes stellt dieser fiktive Brief darüber hinaus auch ein letztes, aussagekräftiges Beispiel für das Ausmaß an pragmatischer Schriftlichkeit dar, das wir im Zusammenhang mit dem antihussitischen Handelsverbot voraussetzen dürfen. Die Schriftstücke über das antihussitische Handelsverbot wie die einschlägigen päpstlichen und königlichen Mandate, Förderbriefe zur Kontrolle des Handelsverkehrs, Beschwerdeschreiben über die Beschlagnahme von angeblichen Schwarzhandelsgütern, Urfehdebriefe mutmaßlicher Hussitenhändler, diplomatischen Korrespondenzen über die Umsetzung des Verbotes, etc. waren offensichtlich so zahlreich und alltäglich, dass die Zeitgenossen sich nicht sonderlich an fingierten Urkunden und Briefen zu diesem Thema stießen. Mit anderen Worten: Die bemerkenswert intensive Schriftlichkeit des spätmittelalterlichen Krieges brachte nicht nur jene wenigen Schriftstücke über das antihussitische Handelsverbot hervor, die heute noch überliefert sind, und jene vielen, deren Existenz sich aus anderen Quellen erschließen lässt, sondern sogar ein paar, die es gar nie tatsächlich gegeben hat.

\section{Listiny a listy o protihusitské obchodní blokádě}

Předložená studie analyzuje listiny a listy, které vznikaly v souvislosti se zákazem obchodování s husity. Zákaz byl vydán papežem Martinem V. a králem Zikmundem Lucemburským a měl platit mezi léty 1420 až 1436. O 30 let později během války mezi římskou kurii a utrakvistickým králem Jiřím z Poděbrad byl tento zákaz opět obnoven. V první části jsou představeny různé druhy listin a listů týkajících se obchodní blokády a jejich klasifikace z hlediska pramenné kritiky. Zvláštní pozornost je věnována těm diplomatickým aspektům, které umožňují poznat místo zkoumaných písemností v každodennosti husitských válek. V druhé části se autorka snaží rekonstruovat ztracené listiny a listy o obchodní blokádě v ostatních pramenech. Dochází přitom k závěru, že existoval několikanásobně větší počet písemností, než je možné dnes usuzovat na základě současného dochování. Platí to zejména pro tzv. doporučující (neboli fedrovní) listy (něm. Förderbriefe). Tento druh písemnosti byl soustavně využíván katolickou stranou k udržení si obchodního provozu pod kontrolou a k zamezení špionáže. Možnosti dochování těchto písemností v archivech byly však velmi omezené. Třetí část studie se věnuje zveřejňování papežských a královských mandátů ohledně zákazu obchodování s husity. Všechny tři části studie vytvářejí celkový obraz o intenzivním využívání pragmatických písemností římskou kurií a katolickými panovníky během husitských válek. 